\title{
Narrative as a Pedagogical Approach to Teaching Leadership and Engineering
}

\author{
Penny Kinnear \\ Annie Simpson \\ University of Toronto \\ penny.kinnear@utoronto.ca \\ annie.simpson@utoronto.ca
}

\begin{abstract}
Making the link between theory and practice remains one of the most challenging tasks in engineering education. Leadership, as one of the desired educational outcomes, presents the same challenge: how to move from theory to practice or how to leverage theory and practice to develop leadership skills and attitudes. Simply learning about leadership does not guarantee a student can act as a leader effectively in a variety of situations.

"The Power of Story: Discovering Your Leadership Narrative" uses narrative to link theory and practice. Narrative provides opportunities for students to learn about relational and authentic leadership as they examine, reflect on personal experiences and learn about themselves as leaders. Narrative is used both as a source of information about leadership and leadership practices, and as a tool for reflecting on and making meaning from experience, [2], and finally, as a means of sharing those meanings with others.

This paper examines the design and development of a course grounded in narrative as both process and product of learning. Pedagogical decision made in the design of the course will be discussed. These include decisions made to foster the trust and commitment to the class necessary to establish a safe space for personal exploration, the tension between the need to evaluate student subject knowledge and evaluating personal growth, the challenge moving students from learning as product to learning as process and product.
\end{abstract}

Keywords: leadership theory, story-telling, life history, narrative theory, experiential learning

\section{INTRODUCTION}

Leadership and communication are two subjects that are often presented as skill sets that an individual can learn and enact when the need arises. The Canadian Engineering Accreditation Board mandates graduate outcomes in teamwork and communication. The University of Toronto has defined these as: "Demonstrate ability to promote team effectiveness through individual action" that includes the demonstration of effective communication and trust and accountability. Students are also expected to "demonstrate the ability to use different modes of communication" which include being able to tailor the form to the audience and purpose of the communication. The teamwork requirements imply an ability to exercise leadership as needed in the diverse team configurations that will arise through an engineer's career.

Communication is critical in the team context as a leadership tool as well as outside of team contexts. Engineers communicate with many different individuals and groups and must have a full repertoire of modes at their disposal. However, if we examine both leadership and communication more closely (and more honestly) although there are specific skills involved, skills alone are not sufficient. Leadership and communication are complex concepts and practices. Becoming adept communicators and leaders requires an understanding of the concepts at a theoretical and practical level. Leadership and communication need to be experienced and repeatedly practiced. Leadership and communication also need to be investigated and explored intellectually. Experience, practice, and intellectual exploration are necessary in order for new knowledge to emerge and transformational learning to take place [9] [15].

This paper first introduces narrative as a process (a method for telling ones stories and sharing experiences) and a product (an artifact that can be examined and reflected on) that affords students opportunities to make links between theories of leadership and their experiences and practice of leadership. Next, the major pedagogical decisions made in the design of the course are introduced and discussed. The paper concludes with a short discussion of the implications of using narrative to foster learning and as a communication mode.

\section{NARRATIVE AS METHOD FOR LEADERSHIP AND COMMUNICATION}

"The Power of Story: Discovering Your Leadership Narrative" is a course about story telling and selfdiscovery focused on the meaning and practice of leadership within the profession of engineering. The 
course acknowledges the centrality of narrative as product and process in exercising leadership in diverse situations. For example, a narrative can be used to inspire action, to deepen relationships, or to transmit knowledge. Through examination of experience, exposure to narrative structure, practice at 'telling' and reflection on meaningsmade, students are supported to recognize the storied nature of their lives [2] [14] [5] and to realize that many possible meanings can be made (some more empowering and self-respecting then others). Students are introduced to the idea of interrogating or resisting accepted narratives and the possibility of alternative narratives. It is not just the stickiness that Heath and Heath [9] have pointed out for the purpose of marketing, it is also the stickiness and the resonance it can create with a group or a team or in communicating with any of the diverse audiences an engineer will address.

It is a course that aims to build students' confidence by having them share their life experiences; reflect deeply on themselves, their values, their identities and their desired futures. The course also introduces students to the structure of narratives and the tools they can use to construct their narratives that can lead to greater understanding and engagement on the part of listeners.

\subsection{Narrative as Link Between Theory and Practice}

Students must have hands-on opportunities to practice various skills as well as opportunities to develop conceptual understanding of both communication and leadership. Narrative provides a unique method through which students can learn about leadership and with which they can position themselves within the profession. The course has been designed to provide affordances that students may use to identify their own leadership characteristics and values. Narrative provides an artifact that students can use to examine their experiences from new perspectives, creating the opportunity for new awareness and personal/professional development to occur.

Leadership is defined and understood in many different ways, as is leadership development. As part of ILead, the instructors approach the course with the belief that leadership is available to all students; that it is not tied to a position, and that leadership is inherently a relational process. The leadership philosophy of ILead emphasizes self-awareness as foundational to leadership effectiveness and holds that 'authentic leadership comes from embracing who we are' [10] By becoming more familiar with and open about personal values, beliefs, pivotal experiences, identity, biases, and strengths, students increase their awareness of self and their capacity to connect with, and positively influence others. Narrative provides the artifacts that students may reflect on and analyze to gain a deeper understanding of themselves.
Students are introduced to the work of Bruner, McAdams, James Paul Gee, Kenneth Kong, Bill George [2] [14] [4] [13] [5] in order to help them understand what they can learn from an examination of their own narratives.

Communication is integral to the exercise of leadership. Students learn that communication is more than the simple sender-receiver model. Communication involves a reciprocal relationship between people, an awareness of the purpose of the communicative event, the relationship between the speaker and listener(s) or reader(s) and an awareness and control of the various modes and communication tools that may be used. Halliday's work informs this conceptualization, as well as that of James Paul Gee [6] [3]. The course deliberately introduces the ideas of field, tenor, and mode [6] to give students a way of understanding the complexity of communication and range of decisions they must make as they plan and deliver their narratives. This is further complicated with the introduction of classic narrative structure. Communication requires that the people involved in the communication build shared meaningeven if that meaning is that they disagree.

The instructors emphasize these two parts of the course as a unity of the theory and the practice. This means that students are expected to both practice and think about what they are practicing. Narrative is an effective tool for this kind of instruction.

\subsection{Narrative as Process and Product}

Narrative, as a process of making sense of the world, also serves as a tool that can be used to make sense of one's self, one's identities and values. On the one hand, narrative is used as a reflective practice that affords students the opportunity to become aware of their own values and the prioritization of those values, especially in relation to the practice of their profession, engineering. In order to do that students are introduced to the theory behind narrative as a sense-making or meaning-making activity through readings and lectures. Narrative is also explored as a mode of communicating with others. Students are introduced to the theory underpinning this aspect of narrative as well, including a typology of narrative [1] and classical narrative structure [2]. Thus, narrative is used as both process and product and incorporates both theory and practice.

Narrative is used in the course as a tool for students to explore their own experiences and the meanings that they have ascribed to their experiences. The instructors encourage students to question their initial interpretations and reflect on their lives and identities from a strengthsbased perspective. Students are encouraged to examine their narratives from different perspectives in order to learn what other meanings may be construed.

Students also become more aware of and have multiple opportunities to practice their presentation skills, to learn 
and understand the structure of a narrative and to understand that narrative is not the same thing as just "telling a story" or anecdotes. Such an approach requires commitment to more than clear articulation, wellorganized messages and eye contact. Understanding the principles of narrative structure helps students become aware of the ubiquitous nature of narrative, even in their engineering work and of its power.

\section{PEDAGOGICAL DECISIONS}

The course 'The Power of Story: Discovering Your Leadership Narrative' is a one-term course that meets for 3 hours once a week. The Institute for Leadership Education in Engineering (ILead) and the Engineering Communication program (ECP) jointly offer the course. It is collaboratively taught by one instructor from each program. The course is open to all engineering students from second year on and can be counted as one of students' required humanities credits or counted toward a Leadership or Communication certificate.

As one instructor comes from an applied linguistics and multilingual educational background and another comes from an education/psychology background, they each bring different theoretical frameworks and practical experiences to the course. These create a healthy tension that allows them to create a much richer course than either of them could create on their own. They collaborate on choosing readings, planning the order and pace of the instructional activities and the design of evaluation rubrics. Both instructors are present in each class as they both take responsibility for different instructional activities during the weekly three-hour time block.

\subsection{Establishing the environment}

A critical element of this course is the creation of a community of trust where personal narratives can be shared and meaningful reflection can occur. Leadership, whether in a design team or a professional team requires trust, the ability to listen, confidence in ones' voice and a clarity of purpose. All of these attributes are fostered throughout the arc of this course. Layered onto the process of narrative practice and into the course assignments are an exploration of identity theory, leadership theory, narrative theory, performance skills and the interrogation of prevalent 'engineering narratives' and meta-narratives to engage critical thought [1] [2]. Asking students to take advantage of these opportunities, requires that the instructors establish that sense of safety.

If students are asked to share personal stories and engage in an examination and critique of their own experiences, they must feel safe. As the course draws from second to fifth-year students, this means that although some of the students may know and have worked with one another prior to this course, many of them are strangers to one another on the first day of class. The instructors have made three important decisions with regard to the first day of class and the first assignment to foster a 'safe' space. These include modeling the delivery of a personal narrative, introducing a framework on levels of listening and choosing a topic for the first narrative that students share. The two instructors each share a short, personal narrative of what brought them to this particular course. The instructors are explicit about listening as the corollary to speaking. They also address the purpose of feedback and critique - as information that is intended to help the student improve the quality of the narrative, never as a judgment on the individual.

The first assignment comprises a childhood narrative that is first shared with only three other people, more as a conversation than a performance. The decision to begin with a childhood story is deliberate. Most students have a repertoire of childhood stories, often funny, often containing experiences common to most of the students in the classroom. These are 'safe' stories to share and to use to practice structuring and developing an engaging narrative. Students have an opportunity to work with this small group and get the group's responses and questions during the second class meeting. The group's responses can help students develop and refine their narratives. The childhood narrative is performed for the same small group during the following class (the third week). In preparation for this first performance, students have a chance to reflect on their narrative, apply insights from a structural analysis of an oral narrative and use their classmates' questions to choose details that will bring the narrative to life. With each successive narrative (engineering, leadership, final narrative) the audience grows until the leadership narrative is performed for half of the class and the final narrative performed for the entire class and invited guests.

These initial decisions and activities that occur within the first three meetings of the course have, thus far, worked to establish a sense of trust and safety in the class. The instructors have witnessed this trust grow to the point that a number of students end up taking risks with both content and form in their final narratives.

\subsection{Designing assignments to link theory and practice}

The course has, as one of its main goals the establishment of a working connection between theory and practice both in the understanding of narrative and in the practice of leadership. To establish this connection, the instructors created a variety of assignments. There are four performance assignments: a childhood narrative, an engineering narrative, a leadership narrative and a final narrative that can focus on any aspect of themselves (engineering identity, aspirations, career trajectory, etc.) 
that the students want to share with others. While these are primarily performance assignments, there are also a number of assignments that require students to apply and make explicit reference to the theory introduced in the lectures and readings. For example, the third narrative assignment also contains a reflective analytical component that requires the students to explicitly address the decisions they made in the construction of their narrative and to link those with the narrative structure theory and performance theory introduced in the class.

There is an in-class collaborative assignment where students view an engineering focused TedTalk and then deconstruct it to identify the different levels of narrative, using a typology of narrative introduced in the readings and lecture [1] and analyze the different engineering narratives looking for the values and perspectives they convey and how those position engineering in relation to society.

The leadership narrative is the most carefully scoped narrative assignment. The instructors deliberately limited the scope to encourage students to examine an example of having experienced leadership either from the position of leader or from the position of working with an effective leader. Students must analyze the experience using the concepts of leadership presented through the readings and lectures [5] [3] [7]. The instructors believe that this affords students an opportunity to make explicit links between their experience and a theoretical understanding of that experience that can contribute to a deeper understanding of the concepts of leadership.

The final narrative assignment comprises both a performance and a reflective analysis. The students submit a 'process summary' that details the decisions they made in the design and planning of their narrative. These decisions include structure, details, performance plans and decisions, etc. The students use the process summary as the basis for a theoretical analysis of their narrative. This provides students with an opportunity to reflect on and demonstrate their understanding of the theory that has informed their decisions.

\subsection{Spanning Ontological to Meta-Narratives}

Part of leadership development relates to critical thought. It is not enough to reflect on one's self in isolation. The instructors intentionally included an exploration of narrative at four levels; ontological, discipline, public and meta-narratives [1] and how these levels interact to support, challenge and re-construct one another. Students live in a complex world where some voices and opinions are heard more than others. This requires an awareness of and ability to identify the differing perspectives present in all levels of narrative. Students are encouraged and supported in their examination of the perspectives and their impact throughout the course, beginning with the questions,
"Whose voice is heard in this story? Whose voice is not heard in this story?" This initial reflection is meant to encourage a broader and more nuanced view of the social world. Materials used to engage in this kind of reflection include the engaging and complex narrative from Thomas King's, The Truth about Stories, [11] that contains a First Nations creation story as well as the narrative of King's mother who worked as an engineer on a team of men but was classified and paid as a production assistant. This is used to engage students in a discussion of prevalent values and their impact on professional and organizational culture. It also lays the foundation for exploring issues around gender and in particular narratives that relate to women and leadership. This layer of the course is essential for equipping students with the tools to become more aware of the assumptions and values that inform the cultures and practices of society as they launch themselves into their chosen profession.

\subsection{Evaluation}

The method of providing the evaluation results and feedback to the students is also designed to establish a dialogue between instructors and students. Students record their performances and send them to the instructors by email. Instructors listen to the performances, record their feedback and return that feedback to the students as an mp3 email attachment. Recording feedback allows the instructors to include tone and affect more effectively than in written feedback. It can also allow the modeling of effective vocal techniques used in narrative. Students have reported that they will listen to the feedback multiple times, usually consulting it during the process of preparing the next narrative.

A major challenge encountered relates to the criteria by which students' narratives are evaluated. There can be many different kinds of risk-taking in these assignments. For some students that might mean making some kind of public disclosure of a personal nature and for others it may mean using a multi-voiced dramatic narrative construction. The instructors have agreed that neither one of these kinds of risk-taking is privileged over the other.

Another area of tension in evaluation comes from the nature of personal growth. First, students in the class range from second year to fifth year (students who are completing their degree having taken a Professional Experience Year, PEY). This means that they are diverse in their experiences, confidence and maturity. Not all students are ready or capable of plumbing the same depths of their values and identities as others. [12] [6]. Although the instructors expect students to engage in the reflective exploration of values, assumptions and behavior they cannot expect all students to do so to the same depth or reach the same goals and therefore cannot evaluate their growth against an outcome standard, as is usually done with pedagogical outcomes for a course. In addition 
to this, the two instructors are grounded in different disciplines, they respond to different aspects of student performance. To address the different perspectives that the instructors bring to evaluation, they have designed evaluation criteria that reflect both perspectives. They engage in careful benchmarking of each assignment, openly acknowledging how and what they value in order to keep their own biases in check. Evaluation practices address these issues in a number of ways. First, in the performance assignments students are evaluated separately on the structure of their narratives (application of the theory of narrative form) and performance. Second, there are two kinds of assignments students are evaluated on-performance assignments and "application of theory" assignments. In this way, no student is excessively penalized because of a struggle with public performance or not having travelled as far in their personal maturity as other students. And finally, each student has two narrative assignments marked by one instructor and two marked by the second instructor, thus providing the student with the perspective and feedback that both instructors bring to the assignments. Such practices demand a significant investment in the time allocated to marking, however, students receive the benefit of more actionable feedback from multiple perspectives.

\section{CONCLUSION}

Designing a course to provide opportunities for students to make explicit and immediate connections between the theoretical aspects of the content and their own practice of the content is challenging. It is especially challenging when working with such abstractions as effective leadership and communication. The instructors of this collaboratively taught course have found narrative as both process and product an effective method of facilitating students to make those connections. The instructors have also found that there needs to be sufficient emphasis placed on the theoretical grounding of both leadership and narrative in order to overcome initial responses to the assumptions that "anyone can tell a story" and "leadership requires a charismatic personality.

Narrative both fosters and requires a trusting relationship between teller and listener. This sense of trust is also essential in a class that asks students to examine their own lived experiences in order to become aware of and willing to use their own leadership strengths.

Evaluation of student achievement in such a course is challenging, however, the instructors have attempted to design an evaluation system that differentiates between what can and cannot be measured as an outcome in the length of one term.

\section{Acknowledgements}

CEEA16; Paper 50

Dalhousie University; June 19 - 22, 2016

-5 of $6-$
The authors would like to thank the Dean for her support of ILead and the ECP. They would also like to thank the Directors of ILead and the ECP for their support of this collaborative course.

\section{References}

[1] M. Baker, Translation and Conflict: A Narrative Account. New York: Routledge Press, 2006, 206 pp.

[2] J. Bruner, "Life as narrative," Social Research, vol. 71, pp. 691-710, 2004.

[3] S. Denning, The Leader's Guide to Storytelling: Mastering the Art and Discipline of Business Narrative. San Francisco: Jossey-Bass, 2011.

[4] J. P. Gee, An introduction to discourse analysis: Theory and method. New York: Routledge, 1999.

[5] B. George, Discover Your True North: Becoming an Authentic Leader. Hoboken, NJ: Wiley, 2015, 320 pp.

[6] C. Gilligan. In a different voice: Psychological theory and Women's Development. Cambridge, MA: Harvard University Press, 1982, 184 pp.

[7] D. Goleman. Primal leadership: Learning to lead with emotional intelligence. Boston: Harvard Business School Press, 2002.

[8] M. A. K. Halliday, On Grammar vol. 1. London: Continuum, 2002, 442 pp.

[9] C. Heath and D. Heath, Made to stick: Why some ideas survive and others die. New York: Random House, 2007.

[10] iLead, Visioneering: iLead's vision, values, philosophy, and mission. Available as of November 2012 from http://ilead.engineering.utoronto.ca/files/2013/07/ILeadVisioneering-Nov-2012.pdf

[11] T. King, The Truth About Stories. Toronto, Canada: House of Anansi Press, 2003, 176 pp.

[12] D.A. Kolb, Experiential Learning Experiences as the Source of Learning and Development, $2^{\text {nd }}$ Edition. New Jersey, USA: Pearson FT Press, 2014, 416 pp. \{ISBN10: 0133892409\}

[13] K. Kong, Professional Discourse. Cambridge University Press, 2014. \{ISBN 978-1-107-02526-4\}

[14] D.P. McAdams, The Stories We Live By: Personal Myths and the Making of Self. New York: Guilford Press, 1997, $336 \mathrm{pp}$.

[15] E O'Sullivan, Transformative Learning: Educational Vision for the $21^{\text {st }}$ Century. Toronto: University of Toronto Press, 1999. 
Proc. 2016 Canadian Engineering Education Association (CEEA16) Conf.

CEEA16; Paper 50

Dalhousie University; June 19 - 22, 2016
-6 of $6-$ 